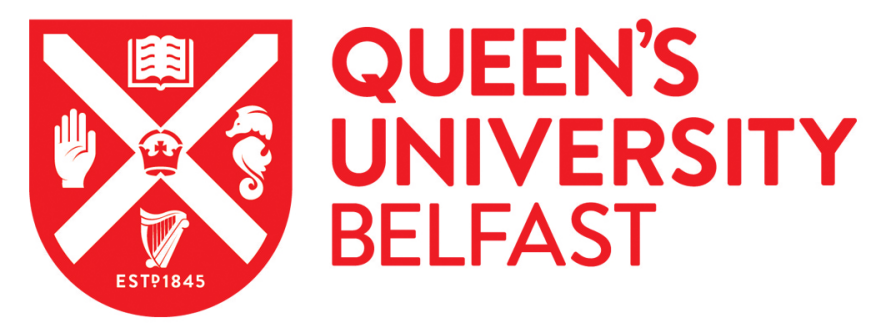

\title{
Hidden Gems: systematically searching electronic databases for research publications for social work and social care.
}

Taylor, B. J., Dempster, M., \& Donnelly, M. (2003). Hidden Gems: systematically searching electronic databases for research publications for social work and social care. British Journal of Social Work, 33(4), 423-439. https://doi.org/10.1093/bjsw/33.4.423

\section{Published in:}

British Journal of Social Work

\section{Document Version:}

Early version, also known as pre-print

Queen's University Belfast - Research Portal:

Link to publication record in Queen's University Belfast Research Portal

\section{General rights}

Copyright for the publications made accessible via the Queen's University Belfast Research Portal is retained by the author(s) and / or other copyright owners and it is a condition of accessing these publications that users recognise and abide by the legal requirements associated with these rights.

Take down policy

The Research Portal is Queen's institutional repository that provides access to Queen's research output. Every effort has been made to ensure that content in the Research Portal does not infringe any person's rights, or applicable UK laws. If you discover content in the Research Portal that you believe breaches copyright or violates any law, please contact openaccess@qub.ac.uk. 


\title{
Hidden Gems: Systematically Searching Electronic Databases for Research Publications for Social Work and Social Care
}

\author{
BRIAN J. TAYLOR, MARTIN DEMPSTER and MICHAEL DONNELLY
}

Brian Taylor has been in social work for 20 years and is currently a Research Fellow in community care. Martin Dempster is a former Research Fellow in community care and is now a Lecturer in Psychology. Michael Donnelly is Reader in community care research. The authors are members of a research group at Queen's University Belfast investigating community care issues.

\section{ABSTRACT}

Context: Electronic bibliographic databases are a key source for professional publications about social work and community care more generally. This article describes and evaluates a method of identifying relevant articles as part of a systematic review of research evidence. Decision making about institutional and home care services for older people is used as an example.

Method: Four databases (Social Science Citation Index, Medline, CINAHL, and Caredata) that abstract publications relevant to health and social services were searched systematically to identify relevant research studies. The items retrieved were appraised independently using a standard form developed for the purpose. The searches were compared in terms of sensitivity, precision, overlap between databases, and inter-rater reliability.

Results: The search retrieved 525 articles, of which 276 were relevant. The four databases retrieved $55 \%, 41 \%, 19 \%$, and $1 \%$ of the relevant articles respectively, achieving these sensitivities with precision levels of 54\%, 48\%, 84\% and $94 \%$. The databases retrieved 116, 73, 24 and 15 unique relevant articles respectively, showing the need to use a range of databases.

Discussion: A general approach to creating a search to retrieve relevant research has been developed. The development of an international, indexed database dedicated to literature relevant to social services is a priority to enable progress in evidence-based policy and practice in social work. Editors and researchers should consider using structured abstracts in order to improve the retrieval and dissemination of research.

Correspondence to: Brian Taylor, Queen's University Belfast, Department of Epidemiology and Public Health, Mulhouse Building, Royal Victoria Hospital, Grosvenor Road, Belfast BT12 6BJ Northern Ireland

E-mail: b.j.taylor@qub.ac.uk 
The first section of this paper gives the context in terms of evidence-based practice in social work, and the development of systematic reviews of research literature. The second section discusses the method used to retrieve relevant research on decision making about the provision of community care services for older people. The following sections evaluate the search methodology and discuss the general implications for accessing research relevant to social work.

\section{CONTEXT}

Just as Sidney and Beatrice Webb sought evidence in order to increase the effectiveness of their campaigns to reform social policy (cf. Webb \& Webb, 1932), so social work has always had formal and more informal research that has influenced policy and practice. In that sense, practice has always been "evidencebased". So what has changed that Trinder can claim, "the emergence of evidencebased practice has to be one of the success stories of the 1990s" (Trinder, 2000, p.1)? Perhaps it is because the time has come to question beliefs in particular methods that have not been tested sufficiently in the past (cf. Bilsker \& Goldner, 2000). Perhaps it is the broader movement in public services requiring accountability for decisions relating both to policy and to practice (see e.g. Davies et al. (eds), 2000). Perhaps it is the gap that some see between the interests of the everyday work of practitioners, and some of the studies carried out by researchers (cf. Seidl, 1991).

In one sense the virtues of basing one's practice on the best available evidence are self-evident, as professionals (1) seek the best practice in a particular circumstance for the benefit of the client; (2) seek to make the best use of resources; and (3) seek decisions that are based on professional knowledge rather than dominated by organisational "requirements" (cf. Webb, 2001). On the other hand, there are the critics who see the present wave of enthusiasm as overly simplistic and constraining professional autonomy (see e.g. Trinder, 2000), just as there have been critics in other professions including medicine (see e.g. Dickersin \& Berlin, 1992). There are those who prefer the term "research-minded" practice (Thompson, 2000), thereby weakening the challenge to create sound research evidence to shape practice. Some see the technical aspects as being in conflict with value issues, although the social work role has always involved contributing professional knowledge and skills within a process that includes client and professional values (see e.g. Taylor \& Devine, 1993). It is interesting that similar debates have occurred in other professions (e.g. McAlister et al., 2000).

The surge of interest in evidence-based practice certainly seems to be linked to the "information age" in which we live, although current concerns such as "the range of information sources available to practitioners ... is growing at a bewildering rate" (Needham, 2000), are strangely reminiscent of Olive Stevenson's lament about "the knowledge explosion" in this journal thirty years ago (Stevenson, 1971). The accumulation of research findings makes the integration of knowledge into 
practice based on best evidence increasingly complex for the practitioner (cf. Petitti, 1994), and more systematic approaches to this are now required.

The methodology of reviewing and synthesising the results of previous research is now generally known as a "systematic review" (Dempster, 2002). A systematic approach to reviews is used in order to minimise bias and random errors (cf. Cook et al., 1997) and to set studies in their proper context (cf. Clarke \& Chalmers, 1998). The process of a systematic review is documented so that it has the validity of being reproducible (Chalmers, 1994). Medical sciences have been at the vanguard of the rising interest during the 1990s, with a focus on the evaluation of interventions, particularly the synthesis of drug trials (Clarke \& Stewart, 1994). However early references to the systematic pooling of research results (Light \& Smith, 1971) and the use of the term "meta-analysis" to refer to the statistical aggregation of data (Glass, 1976; Glass et al., 1981; Hunt, 1997) seem to have been in the field of social and educational sciences. The term "meta-synthesis" has also been used in relation to synthesising the results of qualitative studies (Sandelowski et al., 1997). The Campbell Collaboration (http://campbell.gse.upenn.edu) is now developing an international partnership to coordinate systematic reviews in the field of social and educational sciences (Schuerman et al., 2002), paralleling and drawing on the equivalent Cochrane Collaboration (http://cochrane.org) for health care.

Our purpose in this article is to report on the appropriateness and effectiveness of a methodology for accessing relevant research, leaving aside for now the process of synthesising results. The continually evolving computer technology has produced tools to identify relevant studies much more efficiently and comprehensively than by manual methods (see e.g. Avenell et al., 2001; Taylor, 2002), using nationally networked electronic databases that are designed to meet the needs of professionals and academics, and which are accessible through the World Wide Web. Some key databases for the social work profession are listed in Figure 1.

[Figure 1 near here]

This paper illustrates a methodology for identifying relevant published research (and previous reviews of research) in the context of an ongoing systematic review of decision-making about long term care for older people. The question addressed by the search was framed as: "how are decisions made about the entry of people aged 65 years and over to institutional and home care services?" The search was limited to publications from 1985 to the date of the search in March 2001 in order to include research recent enough to be relevant, but encompassing research on the significant policy developments in the early 1990s in Great Britain and Northern Ireland (National Health Service and Community Care Act, 1990; DHSS (NI), 1990). The search was confined to publications in the English language for practical reasons. This paper focuses on specific issues related to the search methodology, and seeks to address the broader question of the feasibility and 
usefulness of this approach for the social work profession, and for those working in community care more generally.

\section{METHOD}

\section{Selection of Databases}

The following databases were selected: Social Science Citation Index (SSCI), Medline, Cumulative Index of Nursing and Allied Health Literature (CINAHL) and Caredata. All of these databases include abstracts for most (even if not all) of the items for which they provide bibliographic data, and this was the first selection criterion, as citations alone are much less helpful than abstracts in identifying eligible studies (cf. Petrosino et al, 2000). The Social Science Citation Index was selected because of its scope as a major database for the social sciences. Medline and CINAHL were selected because a preliminary scoping study had indicated that material on this topic was published in journals abstracted onto these major databases for medicine and nursing respectively. Caredata was selected because it is the dedicated UK database for social work, now provided as part of the national Electronic Library for Social Care (http://www.elsc.org.uk).

\section{Development of Search Formulae}

At their simplest level, electronic bibliographic databases can search for "text terms" similar to the way that electronic library catalogues now operate. However bibliographic databases of journal articles can search abstracts (and sometimes additional keywords) as well as titles, and are also able to work with combinations of terms using developments of standard Boolean algebra (Taylor, 2002). In addition, of the four databases that we use here, Medline, CINAHL and Caredata have the feature of a thesaurus of terms that is used to index articles on the database. This indexing facilitates retrieval of articles even where terminology differs between publications. By contrast, the search of SSCI (which does not have an indexing system) required the development of terms to cover different spellings and parts of speech (e.g. "care manager" and "care management"), and the varied uses of language across countries and professional disciplines. The formulae devised to search the four databases are shown in the Appendix. A standardised structure has been developed that we intend to test in future with other topics and which may be helpful to the reader (see Figure 2).

[Figure 2 near here]

\section{Sensitivity of Searching}

The sensitivity of a search refers to its capacity to identify as many as possible of the total available relevant articles. More specifically, 'sensitivity' can be defined as the number of studies identified by the search of a particular database divided by the total number of known studies. For this exercise, the total number of studies 
that we retrieved across all four databases was used as the measure of the total number of known studies. This ratio was employed to compare the usefulness of the databases using the best feasible search formula on each.

\section{Precision of Searching}

A search may become more sensitive as more terms are added, but it may also tend to retrieve more irrelevant articles. Therefore the precision of a search formula is also important. "Precision" may be defined as the number of articles identified by a search that are relevant (true positives), divided by the total number identified by that search. In other words, precision is a measure of the positive predictive value of the search. The precision of the searches described here was improved using techniques such as:

1. excluding (where possible) studies in which the main focus was terminal illness, learning disability or mental health problems;

2. using more advanced text searching facilities specific to certain databases such as "case management adj 99 community" (Medline) which defines a search for the phrase "case management" within ninety nine words of the word "community" in the title or abstract, thereby seeking to exclude articles referring to such topics as the "case management" by doctors of patients in hospital; and

3. qualifying or excluding words with many varied applications, such as "assessment", because the use of such words without qualifiers produced an overwhelming number of irrelevant retrievals.

The issue of precision can also be measured from the "opposite direction", that is in terms of the number of irrelevant articles generated by the search on a database. For the reader more familiar with this terminology, the results section also gives the percentage of "false positives" (equal to $100 \%$ minus the precision expressed as a percentage).

\section{Searching by Document Type}

Restricting the search by the type of document sought also helps to reduce the number of irrelevant articles retrieved. SSCI has the facility to search by publication type but not specifically for those that are reports of research, or by research design. Medline is designed to facilitate easy retrieval of research that uses the most rigorous experimental methods (particularly randomised controlled trials) on the effectiveness of interventions. CINAHL and Caredata have a facility to identify "research" articles. As far as possible, the facilities on the respective databases were used to confine our search to documents that reported on research using any design or data collection method, or reviews of research.

\section{Selection of Studies}


The next stage in the process was to identify the relevant studies from amongst the items identified by the database searches. A single sided form was developed to aid the evaluation of each item (or "hit") by extracting information in a standardised format so as to minimise random errors (cf. Oxman, 1995). A copy of the form is available from the first author. The first two authors independently applied the form to the abstracts in order to minimise bias (cf. Meade \& Richardson, 1997). In particular, each rater decided independently whether or not an individual article should be included in the next stage of the review. This decision was based on the information provided by the database only, and was guided by the list of inclusion criteria on the form. Each rater had three options: (1) include, (2) undecided and (3) exclude. Where there was a difference of opinion this was discussed with the aim of reaching a consensus. Any disagreements could have been referred to the third author, but in the event this was not necessary.

\section{Evaluation of the Methodology}

A number of criteria were used to evaluate the search methodology:

1. sensitivity and precision as defined above

2. unique articles retrieved, related to the overlap between the journals abstracted onto the databases, giving an indication of the necessity (or otherwise) of using a range of databases, and

3. inter-rater reliability, used not only as a measure of the consistency of the raters, but also as an indicator of the quality of the information available in the abstracts on the databases.

\section{RESULTS}

\section{Sensitivity and Precision}

The number of articles identified on each database, together with the sensitivity and precision of each search are given in Table 1. It is noteworthy that high sensitivity was achieved on both SSCI and Medline; both contained many relevant articles. Caredata is a much smaller database than the others and retrieved very few of the total available articles, but those that were retrieved were nearly all relevant. CINAHL gave a high level of precision, showing what is feasible (in this case at least) on a large indexed database in a human service field akin to social work.

[Table 1 near here]

\section{Unique Articles Retrieved}

The overlap of each database with the others was analysed in terms of the total number of articles retrieved, and also in terms of the number of relevant articles retrieved (see Table 2). The results have been given as numbers and also as a percentage of the number of articles retrieved on that database. 
[Table 2 near here]

There was no overlap between the articles retrieved by Caredata and any other database. The overlap of relevant articles on the three major databases ranged from $10 \%$ to $39 \%$. Approximately $40 \%$ of both total and relevant articles retrieved on CINAHL were also on Medline. Interestingly, of the relevant articles retrieved on SSCI about 19\% were also on Medline but only $10 \%$ were also on CINAHL, suggesting that the medical database may have a greater coverage of social science publications relevant to this area of social work than the nursing one. The number of articles retrieved on one database but no other is illustrated in Table 3, showing clearly how limited a search would be if confined to a smaller number of databases.

[Table 3 near here]

\section{Inter-Rater Reliability}

The similarity of the decisions by the two raters (inter-rater reliability) was measured using a weighted kappa score. This measurement was chosen because disagreements between the raters are not equal in magnitude between the three options. An "include-exclude" disagreement is more significant than an "includeundecided" or an "exclude-undecided" disagreement. Inter-rater reliability is illustrated in Table 4, which gives weighted kappa scores and the percentage agreement between raters for each database.

The nature of the disagreements illustrated a number of factors relating to the initial decisions of the raters, such as:

1. struggles with terminology unfamiliar to either rater, usually that from another country such as "home health care" or "social health maintenance organisation"

2. the use of terminology more familiar within one of our professional disciplines

3. one or other of the raters on occasion using incidental aspects such as the journal title to assist in making a decision where the abstract was not clear, and

4. the quality of abstracts.

The low weighted kappa score (and the relatively high number of undecided 'verdicts' by both raters) for Caredata reflected the general paucity of information in the abstracts on this database compared with the other three.

[Table 4 near here]

\section{DISCUSSION}

\section{Is a Systematic Review of Research Worthwhile?}

A significant finding from this exercise was the discovery of so many relevant articles in a wide range of journals, and across all four databases. For the purpose of evaluating the methodology, this high yield gave us large enough figures for meaningful statistical analysis. For the purpose of synthesising the results of a 
search, the scope would have to be more tightly defined in order to give a manageable number of items. The more common type of social science literature review that uses the publications of some initial chosen authors, and then seeks references from these, would have failed to find many of the relevant items we retrieved. Such a thorough search would not be feasible without electronic databases, and this required detailed attention to constructing search formulae.

Any one database would have produced rather limited results on this topic by comparison with the results obtained using the four databases (cf. similar comments by Dickersin et al., 1994 and Petrosino et al., 2000). We would apply the words of Hay and colleagues to social work and community care: "[Professionals], researchers, librarians and information specialists should be cautious in selecting and relying on any one bibliographic database to provide a comprehensive listing [of relevant research]" (Hay et al., 1996). It is noteworthy that both health care and social science databases provided a significant number of unique, relevant publications, and this may be similar for research relevant to other aspects of social work.

\section{Sensitivity and Precision of Searching}

Any search embodies a balance between sensitivity and precision. In searching for studies on the effectiveness of medical interventions, searches are commonly designed to aim for high sensitivity with less concern for precision. An exercise by Adams and colleagues (Adams et al., 1994) gave an initial sensitivity of $18 \%$ (on Medline) and later an improved sensitivity of $35 \%$ rising to $63 \%$ using a "skilled search" (developed using methods similar to some of our own), but with a precision of only 7\%. The reported rise in sensitivity took place over two decades of publications, and was attributed to improvements in the procedures and terms used for indexing. A more recent study by Hay and colleagues reported sensitivities between $68 \%$ and $88 \%$ (on a different range of databases from the ones described here), with precision rates in the region of $9 \%$ (Hay et. al., 1996). Our sensitivity figures on SSCI and Medline of 58\% and $43 \%$ respectively stand up reasonably well by comparison given that these databases were not designed for social work, and with rather higher precision (54\% and $48 \%$ respectively). It should be noted however that for the exercise described here we have used the total number of items retrieved on these four databases as our standard, rather than measuring against a more comprehensive search that would include a detailed hand search built upon these electronic searches.

Although the common approach in medical sciences is to emphasise sensitivity rather than precision, our conclusion is that often precision will need to be given significant attention in a search in social science disciplines at present. One reason is that systematic reviews in medicine generally focus on synthesising research on outcomes of interventions (rather than processes), and thus frequently deal only with research involving the most rigorous experimental designs. Thus the number of publications is much smaller, and the number of irrelevant articles identified is 
more easily managed. Also, the indexing systems are designed specifically to assist in retrieving research that has used controlled trial designs. Within social sciences, the wide range of research methods and the varied use of terms by different disciplines mean that a lack of precision yields an overwhelming plethora of irrelevant articles.

\section{Quality of Databases}

Caredata was the most "relevant" database for social work, and it was pleasing therefore to see this confirmed by the high precision. However, the database retrieved very little of the total available material. SSCI and Medline both provided a reasonable balance between sensitivity and precision, and retrieved high numbers of unique articles. CINAHL had less coverage of journals with relevant material than these two databases, but the high precision suggests that a dedicated social work database, similarly based on the systems of Medline, could be very efficient.

\section{A Dedicated Social Work Database?}

The lack of a dedicated, international social work database, comparable to that available to medicine and nursing, became very apparent during the exercise. Addressing this deficit would do much to develop a sound foundation for social work research, and to provide improved credibility for the profession.

Our experience of working across these four databases suggests that a system similar to Medline would be the most effective for systematic searching, and a system fully compatible with it would best facilitate the increasing areas of interface between social and health care services (cf. Taylor, 1998 \& 1999). Whilst the citation-searching feature of the Social Science Citation Index may be useful for some purposes, the design of Medline and CINAHL is more suited to a systematic search for all research publications on a particular topic. This is partly because they have the facility to lay out a search clearly on the screen as a sequence of steps, but also because the articles are indexed using a thesaurus of terms agreeable to the profession.

Although SSCI is a large database focusing on social sciences, an indexed database specifically designed for social work would be a significant step forward to improve the ease, sensitivity and precision of searching, as "study authors may not use search terms uniformly" (Fink, 1998, p.34). In defining the terms to include in an index for classifying social work publications, our experience suggests that it would be best to keep close to the Medline terminology as far as possible. CINAHL is based on Medline, but with variations in the thesaurus. For example, Medline offers eight thesaurus terms as options if one types in a search for the word "risk", whereas CINAHL offers over fifty terms. Many of these terms on CINAHL relate to very specific assessment methods, and when searching this seemed to be too detailed because of the time required selecting out undesired items at each stage of 
the search. However CINAHL produced very high precision for our search, and this aspect merits further study.

Medline and CINAHL were the easiest databases to use because of screen layout and indexing, although the fact that they use different classification terms (e.g. for home care services - see Appendix) was not helpful. One weakness of Medline and CINAHL is that they can sort only 200 results alphabetically at a time. Our search on Medline yielded nearly 240 items, and this had to be managed as two separate alphabetical lists. For a more tightly defined search yielding fewer hits this would not be an issue.

One of the weaknesses of SSCI was that it could deal with only 50 terms in the search formula. Whilst this was adequate to run even the relatively complex search that we used (with about 40 terms), it limited the capacity to develop the formula in a systematic way. In the early stages when the search formula was shorter, it was possible to check the effectiveness of adding each individual new term by running a search for, in algebraic language, "(A or B or C) not (A or B)". This identifies the impact of adding term " $\mathrm{C}$ " to the formula involving "A or B" that has already been developed. This technique requires the system to have a capacity to deal with almost double the number of terms contained in the formula that is being used, in this case therefore about 80 terms. This limitation exacerbated the additional work required in using a database lacking an indexing system.

\section{Identifying Articles by Types of Research Method}

It is easier to identify relevant publications if research designs and data collection methods are included clearly in abstracts (cf. a similar comment by Hay et al., 1996). Searchers can then more readily identify articles of interest on the database, without the expense and time of ordering full articles. We would echo the words of Geraldine Macdonald and colleagues that ensuring that such essential data is provided in abstracts, and that there is some standardisation of presentation, "would do much to enable the profession to develop its knowledge base" (Macdonald et. al., 1992, p.623). Adequate information in abstracts is required if indexers are to do their task effectively and efficiently, and this is an essential step towards an effective indexed database for social work. There are implications here both for authors and for journal editors.

The indexing on CINAHL and Caredata of "research" publications was very useful. It would be helpful also if 'the social work database of the future' had an indexing scheme that would enable searching by specific research designs. Given that this exercise has shown the necessity of including health care databases to access the range of relevant research in a regular sphere of social work practice, our conclusion is that a system of classifying research designs across (at least) health care and social work is very desirable. 


\section{Conclusion}

The worldwide development of information science has presented new possibilities and challenges for researchers and for all professionals who need to be knowledgeable about their particular sphere. Nationally networked electronic databases designed for academic and professional purposes provide an opportunity to access research more efficiently and comprehensively than by manual methods, and appropriate searching skills are now essential. In order to progress as a profession social work needs a dedicated, international, indexed database so that researchers, practitioners and policy-makers can readily identify and access relevant previous research.

\section{Acknowledgements}

Brian Taylor is a Research Fellow funded by the Research and Development Office of the Department of Health, Social Services and Public Safety for Northern Ireland. This support is gratefully acknowledged. Views expressed are those of the authors, and do not necessarily reflect the views of the Department.

\section{References}

Adams, C E, Power, A, Frederick, K \& Lefebvre, C (1994) “An Investigation of the Adequacy of MEDLINE Searches for Randomized Controlled Trials (RCTs) of the Effects of Mental Health Care", Psychological Medicine, 24, pp.741748

Avenell, A, Handoll, H H G \& Grant, A M (2001) "Lessons for Search Strategies from a Systematic Review, in The Cochrane Library, of Nutritional Supplementation Trials in Patients After Hip Fracture", American Journal of Clinical Nutrition, $\underline{73}$, pp.505-510

Bilsker, D \& Goldner, E (2000) "Teaching Evidence-Based Practice in Mental Health", in Research on Social Work Practice, 10, 5, pp.664-669

Chalmers, I (1994) "Foreword" in Chalmers, I \& Altman, D G (eds) (1995) Systematic Reviews, BMJ Publishing Group

Clarke, M \& Chalmers, I (1998) "Discussion sections in reports of controlled trials published in general medical journals: Islands in search of continents?" JAMA 280, pp. 280-282

Clarke, M J \& Stewart, L A (1994) “Obtaining Data From Randomised Controlled Trials: How Much Do We Need For Reliable and Informative MetaAnalyses?" in Chalmers, I \& Altman, G (eds) (1995) Systematic Reviews, BMJ Publishing Group, pp. 37-47

Cook, D J, Mulrow, C D \& Haynes, R B (1997) "Systematic Reviews: Synthesis of Best Evidence for Clinical Decisions", Annals of Internal Medicine, 126, (5), pp.376-380

Davies, H T O, Nutley, S M \& Smith, P C (eds) (2000) What Works: Evidencebased Policy and Practice in Public Services, Bristol: The Policy Press 
Dempster, M (2002) "Systematic Reviews" in Miller, R \& Brewer, J (eds) (2002) The A to Z of Social Research, London: Sage

Department of Health and Social Services (NI) (1990) People First: Community Care in Northern Ireland for the 1990's, Belfast: Her Majesty's Stationery Office

Dickersin, K \& Berlin, J A (1992) "Meta-analysis: State-of-the-Science", Epidemiologic Reviews, 14, pp.154-176

Dickersin, K, Scherer, R, Lefebvre, C (1994) "Identifying Relevant Studies for Systematic Reviews", British Medical Journal, 309, pp.1286-1291

Fink, A (1998) Conducting Research Literature Reviews, London: Sage Publications

Glass, G V (1976) "Primary, Secondary, and Meta-Analysis of Research", Educational Researcher, $\underline{5}$, pp.3-8

Glass, G V, McGaw, B, \& Smith, M (1981) Meta-Analysis in Social Research, Newbury Park: Sage Publications

Hay, P J, Adams, C E \& Lefebvre (1996) "The Efficiency of Searches for Randomized Controlled Trials in the International Journal of Eating Disorders: a Comparison of Handsearching, EMBASE and PsychLIT", Health Libraries Review, 13, pp.91-96

Hunt, M (1997) The Story of Meta-Analysis New York: Russell Sage Foundation Light, R J \& Smith, P V (1971) “Accumulating Evidence: Procedures for Resolving Contradictions Among Different Research Studies", Harvard Educational Review, 41, pp.429-471

Macdonald, G, Sheldon, B \& Gillespie, J (1992) "Contemporary Studies of the Effectiveness of Social Work", British Journal of Social Work, 22(6), pp.615-643

McAlister, F A, Staus, S E, Guyatt, G H \& Haynes, R B (2000) “Users' Guides to the Medical Literature: XX. Integrating Research Evidence with the Care of the Individual Patient", Journal of the American Medical Association, 283, (21), pp.2829-2836

Meade, M O \& Richardson, W S (1997) "Selecting and Appraising Studies for a Systematic Review", Annals of Internal Medicine, 127, pp.531-537

Needham, G (2000) "Research and Practice: Making a Difference" in Gomm, R \& Davies, C (eds) (2000) Using Evidence in Health and Social Care, London: Sage Publications \& The Open University

Oxman, A D (1995) "Checklists for Review Articles", in Chalmers, I \& Altman, D G (eds) (1995) Systematic Reviews, BMJ Publishing Group

Petitti, D B (1994) Meta-Analysis, Decision Analysis, and Cost-Effectiveness Analysis, Oxford: Oxford University Press

Petrosino, A, Boruch, R F, Rounding, C, McDonald, S, \& Chalmers, I (2000) "The Campbell Collaboration Social, Psychological, Educational, and Criminological Trials Registry (C2-SPECTR) to facilitate the preparation and maintenance of systematic reviews of social and educational interventions" Evaluation and Research in Education, 14(3\&4), pp. 206-219

Sandelowski, M, Docherty, S \& Emden, C (1997) "Qualitative Metasynthesis: Issues and Techniques" Research in Nursing \& Health 20, 365-371 
Schuerman, J, Soydan, H, Macdonald, G, Forslund, M, deMoya, D, Boruch, R (2002) "The Campbell Collaboration" Research on Social Work Practice 12(2) pp. 309-317

Seidl, F W (1991) "Foreword" in Gibbs L E (1991) Scientific Reasoning for Social Workers: Bridging the Gap Between Research and Practice New York: Macmillan

Stevenson, O (1971) "Knowledge for Social Work" British Journal of Social Work, 1 (2), pp.225-237

Taylor, B J \& Devine, T (1993) Assessing Needs and Planning Care in Social Work, Hampshire: Ashgate

Taylor, B J (1998) "Service Needs and Individual Qualifications - Training Social Workers for the Community Care Policy Initiative and Post-qualifying Credits" Social Work Education, 17(1), pp.77-93

Taylor, B J (1999) "Developing Partnership between Professions in Implementing New Children's Legislation in Northern Ireland" Journal of Interprofessional Care, 13 (3), pp.249-259

Taylor, B J (2002) "Literature Searching" in Miller, R \& Brewer, J (eds) (2002) The A to $Z$ of Social Research, London: Sage

Thompson, N (2000) Theory and Practice in Human Services, Buckingham: Open University Press

Trinder, L \& Reynolds, S (2000) Evidence-Based Practice - A Critical Appraisal, Oxford: Blackwell Science

Trinder, L (2000) "Evidence-based Practice in Social Work and Probation", in Trinder, L \& Reynolds, S (2000) Evidence-Based Practice - A Critical Appraisal, Oxford: Blackwell Science

Webb, S \& Webb, B (1932) Methods of Social Study, Cambridge: London School of Economics and Political Science, and Cambridge University Press

Webb, S A (2001) "Some Considerations on the Validity of Evidence-based Practice in Social Work", British Journal of Social Work, $\underline{31}$, pp.57-79 


\section{Appendix: Search Formulae for the Four Databases}

\section{Search Formula for Social Science Citation Index}

(care manage* OR case manage* OR care at home OR community care OR homecare OR home care OR social care OR care home* OR home* for the aged OR institutional care OR long-term care OR long term care OR nursing home* OR old peoples home* OR old people's home* OR out of home placement*) AND (admit* OR admission* OR allocation OR enter* OR entry OR institutionali?ation OR placement*) AND (decision* OR judg*ment OR risk*) AND (elder* OR geriatric OR old age OR old* people) NOT (hospice* OR learning disabilit* OR mental* disorder* OR mental* handicap* OR palliative care OR terminal care OR terminal illness); DocType=Article, Bibliography, Database Review, Review; Language=English; Databases=SSCI; Timespan=1985，1986, 1987, 1988, 1989, 1990, 1991, 1992, 1993, 1994, 1995, 1996, 1997, 1998, 1999, 2000, 2001

\section{Search Formula for Caredata}

(KEYWORDS of (admission to care/home care) \& (older people with dementia/older people))

and (KEYWORDS ct (assessment/decision making/risk/referral) \& research/applied research))

[appendix continues: note these four tables within the Appendix might be placed in any order to suit the page size, although the order dealt with in the text is SSCI,

Medline, CINAHL, Caredata] 


\section{Search Formula for Medline}

\begin{tabular}{|c|c|}
\hline \# & Search History \\
\hline 1 & “CARE MANAGEMENT”.mp \\
\hline 2 & $\begin{array}{l}\text { (Case management adj99 community).mp. }[\mathrm{mp}=\text { title, abstract, registry } \\
\text { number word, mesh subject heading] }\end{array}$ \\
\hline 3 & exp Home care services/ \\
\hline 4 & exp Homes for the aged/ \\
\hline 5 & exp Long-term care/ \\
\hline 6 & exp Nursing homes/ \\
\hline 7 & 1 or 2 or 3 or 4 or 5 or 6 \\
\hline 8 & "ADMISSION".mp \\
\hline 9 & "ALLOCATION".mp \\
\hline 10 & $\begin{array}{l}\text { institutionali?ation.mp. [mp }=\text { title, abstract, registry number word, mesh } \\
\text { subject heading] }\end{array}$ \\
\hline 11 & exp Needs assessment/ \\
\hline 12 & “PLACEMENT”.mp \\
\hline 13 & 8 or 9 or 10 or 11 or 12 \\
\hline 14 & 7 and 13 \\
\hline 15 & $\begin{array}{l}\text { exp decision making/ or exp decision making, computer-assisted/ or exp } \\
\text { decision making, organiszational/ or exp decision support systems, clinical/ } \\
\text { or exp decision support systems, management/ or exp decision support } \\
\text { techniques/ or exp decision theory/ or exp decision trees/ }\end{array}$ \\
\hline 16 & exp Judgement/ \\
\hline 17 & $\begin{array}{l}\text { exp risk/ or exp risk assessment/ or exp risk factors/ or exp risk } \\
\text { management/ or exp risk-taking/ }\end{array}$ \\
\hline 18 & 15 or 16 or 17 \\
\hline 19 & 14 and 18 \\
\hline 20 & $\begin{array}{l}\text { limit } 19 \text { to (("aged }<65 \text { and over }>\text { " or "aged, }<80 \text { and over }>\text { ") and (clinical } \\
\text { trial or controlled clinical trial or journal article or meta analysis or } \\
\text { randomized controlled trial or review, literature or review, academic) and } \\
\text { english and yr=1985-2001) }\end{array}$ \\
\hline 21 & *Hospices/ \\
\hline 22 & *Learning disorders/ \\
\hline 23 & *Palliative care/ \\
\hline 24 & *Terminal care/ \\
\hline 25 & 21 or 22 or 23 or 24 \\
\hline 26 & $20 \operatorname{not} 25$ \\
\hline
\end{tabular}

[appendix continues] 


\section{Search Formula for CINAHL}

\begin{tabular}{|c|l|}
\hline$\#$ & \multicolumn{1}{|c|}{ Search History } \\
\hline 1 & exp Assisted Living/ \\
\hline 2 & $\begin{array}{l}\text { Care management.mp. [mp }=\text { title, cinahl subject heading, abstract, } \\
\text { instrumentation] }\end{array}$ \\
\hline 3 & $\begin{array}{l}\text { (Case management adj99 community).mp [mp=title, cinahl subject heading, } \\
\text { abstract, instrumentation] }\end{array}$ \\
\hline 4 & exp Homemaker Services/ \\
\hline 5 & exp Homes for the Aged/ \\
\hline 6 & exp Long Term Care/ \\
\hline 7 & exp Nursing Homes/ \\
\hline 8 & 1 or 2 or 3 or 4 or 5 or 6 or 7 \\
\hline 9 & admission.mp [mp = title, cinahl subject heading, abstract, instrumentation] \\
\hline 10 & allocation.mp [mp = title, cinahl subject heading, abstract, instrumentation] \\
\hline 11 & $\begin{array}{l}\text { institutionali?ation.mp [mp=title, cinahl subject heading, abstract, } \\
\text { instrumentation] }\end{array}$ \\
\hline 12 & exp Needs Assessment/ \\
\hline 13 & placement.mp [mp = title, cinahl subject heading, abstract, instrumentation] \\
\hline 14 & 9 or 10 or 11 or 12 or 13 \\
\hline 15 & 8 and 14 \\
\hline 16 & $\begin{array}{l}\text { exp DECISION MAKING/ or exp DECISION SUPPORT SYSTEMS, } \\
\text { MANAGEMENT/ or exp DECISION SUPPORT SYSTEMS, CLINICAL/ } \\
\text { or exp DECISION MAKING, CLINICAL/ or exp DECISION MAKING, } \\
\text { COMPUTER ASSISTED/ or exp DECISION MAKING, ETHICAL/ or exp } \\
\text { DECISION MAKING, FAMILY/ or exp DECISION MAKING, } \\
\text { ORGANIZATIONAL/ or exp DECISION MAKING, PATIENT/ }\end{array}$ \\
\hline 17 & exp JUDGMENT/ \\
\hline 18 & $\begin{array}{l}\text { exp RISK FACTORS/ or exp RELATIVE RISK/ or exp RISK } \\
\text { ASSESSMENT/ or exp RISK MANAGEMENT/ or exp RISK TAKING } \\
\text { BEHAVIOUR/ }\end{array}$ \\
\hline 19 & 16 or 17 or 18 \\
\hline 20 & 15 and 19 \\
\hline 21 & $\begin{array}{l}\text { limit 20 to ((aged <65 to 79 years > or “aged, 80 and over") and yr=1985- } \\
2001 \text { and (book or book chapter or case study or clinical trial or journal } \\
\text { article or legal cases or research or research instrument or review or } \\
\text { systematic review) and english) }\end{array}$ \\
\hline 22 & *Hospices/ \\
\hline 23 & *Learning Disorders/ \\
\hline 24 & *Palliative Care/ \\
\hline 25 & *Terminal Care/ \\
\hline 26 & 22 or 23 or 24 or 25 \\
\hline 27 & 21 not 26 \\
\hline
\end{tabular}


Figure 1 Some Important Electronic Databases for Social Work Professionals

\section{Title of Database}

British Educational Index

Caredata (National Institute of Social Work, London)

Child Data (National Children's Bureau, London)

Cumulative Index of Nursing and Allied Health Literature (CINAHL)

Educational Research Information Centre (ERIC)

International Bibliography of the Social Sciences

LexisNexis (legal database)

Medline (medical database)

PsycINFO and PsycLIT (psychology databases)

Social Science Citation Index 
Figure 2 General Structure of a Search Formula

Type of Service or Intervention Method AND

Particular Aspect of Service (e.g. related to time or process) AND

Client Group(s) AND

Professional Role or Task AND

Publication Limits (e.g. language; research articles; dates of publication) 
Table 1 Articles Identified, Sensitivity and Precision of Searches

\begin{tabular}{lccccc}
\hline & SSCI & Medline & CINAHL & Caredata & $\begin{array}{l}\text { Total } \\
\text { (removing } \\
\text { overlap) }\end{array}$ \\
\hline Articles identified & 283 & 237 & 61 & 16 & 525 \\
Relevant articles & 152 & 114 & 51 & 15 & 276 \\
Sensitivity & $55.1 \%$ & $41.3 \%$ & $18.5 \%$ & $0.05 \%$ & \\
Precision & $53.7 \%$ & $48.1 \%$ & $83.6 \%$ & $93.8 \%$ & \\
False positives & $46.3 \%$ & $51.9 \%$ & $16.4 \%$ & $6.2 \%$ &
\end{tabular}


Table 2 Overlap Between Databases in terms of Number of Articles and as a Percentage of the Articles Retrieved on that Database

\begin{tabular}{|c|c|c|c|c|c|c|}
\hline \multirow[t]{2}{*}{ SSCI with: } & \multicolumn{2}{|c|}{ Medline } & \multicolumn{2}{|c|}{ CINAHL } & \multicolumn{2}{|c|}{ Caredata } \\
\hline & No & $\%$ & No. & $\%$ & No. & $\%$ \\
\hline Articles retrieved & 38 & 13.4 & 17 & 6 & 0 & 0 \\
\hline Relevant articles & 29 & 19.1 & 15 & 10 & 0 & 0 \\
\hline \multirow[t]{2}{*}{ Medline with: } & \multicolumn{2}{|c|}{ SSCI } & \multicolumn{2}{|c|}{ CINAHL } & \multicolumn{2}{|c|}{ Caredata } \\
\hline & No & $\%$ & No. & $\%$ & No. & $\%$ \\
\hline Articles retrieved & 38 & 16 & 26 & 11 & 0 & 0 \\
\hline Relevant articles & 29 & 25.4 & 20 & 17.5 & 0 & 0 \\
\hline \multirow[t]{2}{*}{ CINAHL with: } & \multicolumn{2}{|c|}{ SSCI } & \multicolumn{2}{|c|}{ Medline } & \multicolumn{2}{|c|}{ Caredata } \\
\hline & No & $\%$ & No. & $\%$ & No. & $\%$ \\
\hline Articles retrieved & 17 & 27.9 & 26 & 42.6 & 0 & 0 \\
\hline Relevant articles & 15 & 29.4 & 20 & 39.2 & 0 & 0 \\
\hline \multicolumn{5}{|c|}{ Overlap between more than two databases } & \multicolumn{2}{|c|}{ No. } \\
\hline \multirow{2}{*}{\multicolumn{3}{|c|}{ SSCI with Medline and CINAHL }} & \multirow{2}{*}{\multicolumn{2}{|c|}{$\begin{array}{l}\text { Articles retrieved } \\
\text { Relevant articles }\end{array}$}} & \multicolumn{2}{|c|}{9} \\
\hline & & & & & \multicolumn{2}{|c|}{8} \\
\hline
\end{tabular}


Table 3 Articles Retrieved and Relevant Articles Retrieved Unique to a Particular Database

\begin{tabular}{lcccc}
\hline & SSCI & Medline & CINAHL & Caredata \\
\hline $\begin{array}{l}\text { Unique Articles } \\
\text { Retrieved }\end{array}$ & 237 & 182 & 27 & 16 \\
$\begin{array}{l}\text { Unique Relevant } \\
\text { Articles }\end{array}$ & 116 & 73 & 24 & 15 \\
\hline
\end{tabular}


Table 4 Inter-rater Reliability Results

\begin{tabular}{lcccc}
\hline & SSCI & Medline & CINAHL & Caredata \\
\hline Rater 1 Include & 108 & 83 & 27 & 4 \\
Rater 2 Include & 155 & 106 & 33 & 8 \\
Rater 1 Undecided & 39 & 46 & 18 & 11 \\
Rater 2 Undecided & 9 & 16 & 6 & 7 \\
Rater 1 Exclude & 136 & 108 & 16 & 1 \\
Rater 2 Exclude & 119 & 115 & 22 & 1 \\
Weighted Kappa score & 0.85 & 0.88 & 0.86 & 0.66 \\
Percentage agreement & $77 \%$ & $76 \%$ & $69 \%$ & $63 \%$ \\
\hline
\end{tabular}

